\title{
Establishment of an immortalised human ovarian surface epithelial cell line without chromosomal instability
}

\author{
T Maeda', H Tashiro², H Katabuchi*,2, M Begum', H Ohtake², T Kiyono ${ }^{3}$ and H Okamura' \\ 'Department of Reproductive Medicine and Surgery, Faculty of Medical and Pharmaceutical Science, Kumamoto University, Honjo I-I-I, Kumamoto- \\ City, Kumamoto 860-8556, Japan; ${ }^{2}$ Department of Gynecology, Faculty of Medical and Pharmaceutical Science, Kumamoto University, Honjo I- I- I, \\ Kumamoto-City, Kumamoto 860-8556, Japan; ${ }^{3}$ Virology Devision, National Cancer Center Research Institute, 5-I-I Tsukiji, Chuo-ku, Tokyo I04-0045, \\ Japan
}

Epithelial ovarian carcinoma is thought to derive from ovarian surface epithelium (OSE). The black box of the early molecular changes in ovarian carcinogenesis is being interpreted by the development of experimental systems employing immortalised human OSE cells. However, the existing cell lines of the OSE cells have limited utility due to chromosomal instability. Our goal was to establish new immortalised human OSE cells that retain the original characteristics of the primary cells without chromosomal alterations. Using primary human OSE cells obtained from a postmenopausal patient with endometrial cancer, five cell lines ('HOSEI' lines) were newly established by infection with retroviral expression vectors containing type 16 human papillomavirus (HPV-16) E6, E7, a variant E6 $(E 6 \Delta \mid 5 I)$, and Bmil polycomb gene, in combination with telomerase reverse transcriptase (hTERT). Consequently, five HOSE I s cell lines, HOSEIs-E6/hTERT, -E7/hTERT, -E6/E7/hTERT, -E6 II5I/E7/hTERT, and -E6 1 I5I/Bmil/hTERT, grew beyond the population doubling number of 200. These cell lines, except for HOSEI-E6/hTERT, essentially showed the original features of the primary human OSE cells. Of them, HOSEI-E7/hTERT preserved diploidy in a kariotype analysis, and did not show transformed phenotypes in anchorage-independent growth and tumour formation. Thus, HOSEI-E7/hTERT may provide a novel model system with which to investigate the mechanisms of early molecular changes.

British Journal of Cancer (2005) 93, I I6-123. doi: 10.1038/sj.bjc.6602662 www.bjcancer.com

Published online 14 June 2005

(C) 2005 Cancer Research UK

Keywords: human; ovarian surface epithelium; immortalisation; human papillomavirus; hTERT

\begin{abstract}
Most epithelial ovarian carcinomas are considered to arise from ovarian surface epithelium (OSE), a single continuous layer of flat-to-cuboidal mesothelial cells covering the ovary (Okamura and Katabuchi, 2005). In epithelial ovarian carcinoma, numerous studies have revealed different patterns of genetic change. These include activation of oncogenes (K-ras, HER-2, Src, c-myc, AKT2, PIK3CA and STK/BTAK) through amplification, translocation, or mutation (Slamon et al, 1989; Enomoto et al, 1991; Tashiro et al, 1992; Bellacosa et al, 1995; Zhou et al, 1998; Shayesteh et al, 1999; Wiener et al, 2003), as well as inactivation of tumour suppressor genes (p53, PTEN, WT1, BRCA 1, NOEY2 and WWOX) through homozygous deletion, double mutations, or a combination of mutation and loss of heterozygosity or promotor methylation (Fujita et al, 1995; Obata et al, 1998; Yu et al, 1999; Schorge et al, 2000; Paige et al, 2001; McCoy et al, 2003). Although such genetic changes have long been identified using ovarian carcinoma tissues or cell lines, the early molecular changes in ovarian carcinogenesis have not been fully clarified. In addition, adequate experimental systems and suitable animal models are lacking due to spontaneous epithelial ovarian tumours being extremely rare in nonprimate mammals, including mice. During the last decade,
\end{abstract}

*Correspondence: Professor H Katabuchi;

E-mail: buchi@kaiju.medic.kumamoto-u.ac.jp

Received 27 January 2005; revised 26 April 2005; accepted 18 May 2005; published online 14 June 2005 the isolation, culture, and immortalisation of human OSE cells was developed (Maines-Bandiera et al, 1992; Tsao et al, 1995; Nitta et al, 2001). Using the experimental system of Auersperg et al (1999), E-cadherin expression was recently addressed in human ovarian carcinogenesis (Ong et al, 2000). Furthermore, in the OSE cells, autocrine HGF-Met and LH-LH/hCG receptor loops have been shown to be involved in early carcinogenesis (Wong et al, 2001; Tashiro et al, 2003). Although the system using the immortalised human OSE cell lines would serve as relevant models, the utility of the existing cell lines is limited by their accumulation of chromosomal instability. The establishment of new cell lines without such genetic instability is required to advance further research of carcinogenesis.

The proliferation potential of epithelial cells is determined by three independent stages: mortality stage 0 (M0) Foster et al reported (Foster and Galloway, 1996; Foster et al, 1998), mortality stage 1 (M1) and mortality stage 2 (M2), Shay et al described (Shay et al, 1991; Wright and Shay, 1992). Epithelial cells appear to senesce in initial growth arrest, M0, which is controlled by the p16/ $\mathrm{Rb}$ pathway. Following progressive shortening of telomere length in cell divisions, the next growth arrest, $\mathrm{M} 1$, is induced by telomere shortening and activation of $\mathrm{p} 53 / \mathrm{p} 21$ pathway. When the $\mathrm{p} 16 / \mathrm{Rb}$ and $\mathrm{p} 53$ functions are inactivated, the cells overcome M0 and M1. However, even after epithelial cells have bypassed these stages, telomere shortening continues until the cells reach a crisis, M2, which is characterized by marked chromosomal instability and 
chromosome fusion (Zakian, 1989; Blackburn, 1991). Most of cells die in the crisis, but the remaining small number of cells acquires telomerase activity and prevents the crisis.

Primary human OSE cells have limited proliferative potential and fall into early senescence within 2-8 passages in vitro. Until now, using human OSE cells, two kinds of immortalised cell lines were established by introduction of SV40 large T antigen (LT) (Maines-Bandiera et al, 1992; Nitta et al, 2001) or by human papillomavirus (HPV) E6 and E7 (E6/E7) transduction (Tsao et al, 1995). The OSE cells transduced by SV40 LT and by E6/E7 had chromosomal alterations ranging in number from 50 to 69 (Nitta et al, 2001) and 43 to 88 (Tsao et al, 1995), respectively. These OSE cells were not thought to have active telomerase, and consequently resulted in chromosomal alterations. Hence, we postulated that inhibition of $\mathrm{p} 16 / \mathrm{Rb}$ and/or p53 pathways in combination with activation of telomerase may induce immortalisation, while abolishing chromosomal instability. Our goal was to establish immortalised human OSE cell lines without chromosomal instability, by transducing E6 or a variant E6 with a mutation of PDZ domain-binding site for the inhibition of p53, E7 for the inhibition of $\mathrm{RB}$, and polycomb family transcriptional repressor Bmil for inhibition of p16 (Jacobs et al, 1999), in combination with human telomerase reverse transcriptase (hTERT) for the activation of telomerase.

\section{MATERIALS AND METHODS}

\section{Isolation of human OSE and primary cell culture}

Both ovaries were obtained from a postmenopausal patient undergoing abdominal total hysterectomy and bilateral salpingooophorectomy for endometrial cancer (International Federation of Gynecology and Obstetrics: stage IIIc, TMN classification: pT1bN1M0, peritoneal washing smear: negative) at Kumamoto University Hospital, Japan. The Ethics Committee of Kumamoto University approved this study and the subject gave her informed consent for participation. The ovaries were grossly normal and no pathological lesions were observed by subsequent histological examination. After collagenase digestion under aseptic conditions, the OSE cells were scraped with a surgical blade as described previously (Nakamura et al, 1994). The viability of these cells was more than $95 \%$, as shown by the trypan blue dye exclusion test. Subcultured OSE cells were cultured in Dulbecco's modified Eagle's medium (DMEM)/F12 (1:1 mixture) (Invitrogen, NY, USA) supplemented with $10 \%$ fetal bovine serum (FBS; Thermo Trace Ltd, Melbourne, Australia), $100 \mathrm{U} \mathrm{ml}^{-1}$ penicillin G (P), and $100 \mu \mathrm{g} \mathrm{ml}^{-1}$ streptomycin (S) in a humidified $5 \% \mathrm{CO}_{2}$ incubator at $37^{\circ} \mathrm{C}$. Upon reaching confluency, cells were detached from the dish with $0.125 \%$ trypsin and $0.11 \%$ ethylenediamine tetraacetic acid (EDTA) and split in a $1: 2$ ratio in a new culture dish.

\section{Vector construction and retroviral transduction of E6, variant E6, E7, or Bmil as well as hTERT}

pCMSCVpuro comprises the CMV/LTR fusion promotor, the packaging signal Psi + , and the multicloning sequence from pCLXSN (Imgenex Corp.,. San Diego, CA, USA) followed by the PGK-puro cassette and the $3^{\prime}$ long terminal repeat of murine embryonic stem cell virus from pMSCVpuro (Clontech, Palo Alto, CA, USA). The Gateway system (Invitrogen, Carlsbad, CA, USA) was used for subcloning genes into retroviral vectors. The destination vectors, pCLXSN-DEST and pDEST-CMSCVpuro, were constructed by inserting a modified cassette containing attR sites and $\mathrm{ccdB}$ (Invitrogen) between the XhoI and BamHI sites of pCLXSN, and between the EcoRI and BglII sites of pCMSCVpuro, respectively. Cloning of the full-length hTERT cDNA and human Bmi-1 cDNA has been described previously (Okamoto et al, 2002).
After cloning segments of HPV16 E6 (16E6), E7 (16E7), and a deletion mutant of HPV E6, 16E6SD-d151 (E6 151 ) (Kiyono et al, 1997), these segments were recombined into the retroviral vectors by the LR reaction (Invitrogen) to generate pCMSCVpuro-hTERT, pCLXSN-16E6, pCLXSN-16E6 151 , and pCLXSN-16E7. pCLXSN16E6E7 was constructed by inserting an EcoRI-BamHI segment containing HPV16 E6 and E7 between the EcoRI and BglII sites of pCLXSN. Production of recombinant retroviruses was as previously described (Naviaux et al, 1996). Briefly, retroviral vector and packaging construct, pCL-10A1, were cotransduced into 293T cells using TransIT-293 (Mirus Co., Madison, WI, USA) according to the manufacturer's instructions. The culture fluid was harvested at 48 to $72 \mathrm{~h}$ post-transduction. The titer of the recombinant viruses was greater than $1 \times 10^{5}$ drug-resistant colonyforming units $\mathrm{ml}^{-1}$ on Hela cells. A $1 \mathrm{ml}$ aliquot of the culture fluid in the presence of polybrene $\left(4 \mu \mathrm{g} \mathrm{ml}^{-1}\right)$ was added in 24 -well dishes on which the cells were seeded. Following inoculation with viruses, cells were grown without drug selection as mock-infected cells stopped growing within 2 weeks. To achieve combinations of retroviral infections, cells were infected with LXSN-16E6, LXSN16E7, LXSN-16E6E7, LXSN-hBmi1, or LXSN alone, at passage 2, and subsequently reinfected with MSCV-hTERT at passage 3. Alternatively, the cells infected with either LXSN-16E7 or LXSN-hBmil and MSCV-hTERT were additionally infected with LXSN $-16 \mathrm{E} 6 \Delta 151$ at passage 5 .

\section{Cell culture}

The transduced OSE cells were maintained in DMEM/F12 $(1: 1)$ supplemented with $10 \% \mathrm{FBS}, 100 \mathrm{U} \mathrm{ml}^{-1}$ penicillin $\mathrm{G}$, and $100 \mu \mathrm{g} \mathrm{ml}^{-1}$ streptomycin in an atmosphere of $5 \% \mathrm{CO}_{2}$ at $37^{\circ} \mathrm{C}$. When confluent, transduced cells were trypsinised and subcultured in a split ratio of $1: 4-16$. Cells were defined to be immortalised when the population doubling level of the transduced cells surpassed 100 population doubling levels (Kyo et al, 2003). Cells were seeded into 24 -well plates and each well counted daily. Growth curves were constructed, and doubling times were estimated. The human ovarian cancer cell line, NIH;OVCAR-3 (OVCAR-3), was obtained from Cell Resource Center for Biomedical Research, Tohoku University, Japan, and cultured under the same conditions as the HOSE1s cells.

\section{TRAP assay}

In each of the cell lines, telomerase activity was examined by the telomeric repeat amplification protocol (TRAP) assay using the TRAPeze kit (Intergen, Burlington, MA, USA) according to the manufacturer's instructions.

\section{Western blotting}

A $20 \mu$ g protein sample from whole-cell extracts was separated by SDS-PAGE and blots were prepared on Immobilon-P membrane (Millipore, Billerica, MA, USA). The following antibodies were used as probes: for p53 and p21 proteins, clones DO-1 and EA-10, respectively (Oncogene Science, Cambridge, MA, USA); for Rb and p16 proteins, clones G3-245 and G175-405, respectively (PharMingen, San Diego, CA, USA); for Bmil protein (produced by Kiyono et al, unpublished). Blots were then probed with horseradish-peroxidaseconjugated goat anti-mouse IgG (Jackson Immuno Research, West Grove, PA, USA) and visualised using the chemiluminescence system (Amersham, Biosciences, Piscataway, USA).

\section{Reverse transcriptase-polymerase chain reaction (RT-PCR)}

Total RNA was prepared from the cultured cells using Trizol reagent, as described by the manufacturer. cDNA was synthesised 
from $5 \mu \mathrm{g}$ of total RNA using Oligo $\mathrm{dT}_{12-18}$ Primers (Invitrogen, CA, USA) as the primer and Superscript II Rnase HReverse Transcriptase (Invitrogen). Amplification of E-cadherin was performed for 30 cycles (denaturation for $30 \mathrm{~s}$ at $94^{\circ} \mathrm{C}$, annealing for $40 \mathrm{~s}$ at $57^{\circ} \mathrm{C}$ and extension for $30 \mathrm{~s}$ at $72^{\circ} \mathrm{C}$ ) in a standard $50 \mu \mathrm{l}$ PCR mixture. The reaction mixture contained $1 \mu \mathrm{l}$ cDNA from the $\mathrm{RT}$ reaction, $0.2 \mu \mathrm{M}$ of the first pair of upstream and downstream primers, $5 \mu \mathrm{l} 10 \times$ PCR buffer (Invitrogen), $0.2 \mathrm{~mm}$ dNTP (Invitrogen), $1.5 \mathrm{~mm} \mathrm{MgCl}_{2}$ (Invitrogen), and $5 \mathrm{U}$ Taq DNA polymerase (Invitrogen). The sequences of the RT-PCR primers were $5^{\prime}$-GAGGAGAGCGGTGGTCAAAG- $3^{\prime}$ (sense) and $5^{\prime}$ GTTCAGGGAGCTCAGACTAG-3' (antisense) for E-cadherin to produce a $351 \mathrm{bp}$ PCR product (Nishida et al, 2003). The primer sequences for human glyceraldehyde-3-phosphate dehydrogenase (GAPDH) as internal control were $5^{\prime}$-GAA GGT GAA GGT CGG AGT- $3^{\prime}$ (sense) and $5^{\prime}$-GAA GAT GGT GAT GGG ATT TC-3' (antisense) to produce a $226 \mathrm{bp}$ PCR product. Polymerase chain reaction was carried out in a Thermal Cycler (PC 701; Astec, Fukuoka, Japan). The amplified PCR products were analysed by electrophoresis through $2.0 \%$ agarose gel, visualised by ethidium bromide staining, and photographed under ultraviolet illumination. The $100 \mathrm{bp}$ DNA ladder (BioLabs, Beverly, MA, USA) was used for determining the molecular size of amplified products. OVCAR-3 was employed as a positive control. As a negative control, distilled water was used in place of cDNA in all the reactions.

\section{Immunocytochemistry}

HOSE1s cells were cultured on Lab Tech Chamber slides (Nalge Nunc International, Rochester, NY, USA) for $24 \mathrm{~h}$. They were fixed in $95 \%$ ethanol for $10 \mathrm{~min}$ at room temperature and washed with PBS. Endogenous peroxidase activity was blocked with $0.03 \%$ hydrogen peroxide in methanol for $5 \mathrm{~min}$. The cultured chamber slides were stained with the following mouse monoclonal antibodies: pan-cytokeratine (1:50 dilution, DAKO, Carpinterio, CA, USA), vimentin (1:10 dilution, DAKO), epithelial membrane antigen (EMA) antibody ( $1: 200$ dilution, DAKO), CA125 (1:100 dilution, DAKO), or collagen IV (1:100 dilution, Sigma-Aldrich, St Louis, MO, USA) for $30 \mathrm{~min}$ at room temperature. Staining reactions were performed using the indirect method using an ENVISION + (DAKO). Peroxidase activity was visualised with $3,3^{\prime}$-diaminobenzidine (Sigma-Aldrich) as a substrate in Tris- $\mathrm{HCl}$ buffer $\left(0.5 \mathrm{mg} \mathrm{ml}^{-1} \mathrm{pH}\right.$ 7.6) containing $0.01 \% \mathrm{H}_{2} \mathrm{O}_{2}$. Nuclear staining was performed with Mayer's haematoxylin.

\section{CA125 levels in culture medium}

Medium was changed every 2 days and was taken from cultures with a cell density varying between $0.6-1.7 \times 10^{6}$ cells ml $^{-1}$ growing in $6 \mathrm{~cm}$ dishes. The CA125 in the supernatant was measured by electrochemiluminescence immunoassay using Elecsys CA 125 (Roche Diagnostics K.K., Tokyo, Japan).

\section{Karyotype analysis}

Karyotype analyses were performed at passage 16 and passage 41 for each cell line. Routine karyotypic analysis was performed using preparations stained with $5 \%$ Giemsa solution. In order to identify possible rearrangements, chromosomes of metaphases were G-banded. For each cell line, more than 50 cells were scored for their chromosome number. Chromosomal analysis of the most stable line at passage 41 was added at 60 passage.

\section{Cell proliferation assay (anchorage-dependent growth)}

HOSE1s cells were placed in separate 96-well microtitre plates at a density of $2 \times 10^{3}$ cells well $^{-1}$ and allowed to grow for $24 \mathrm{~h}$ in
DMEM with $10 \%$ FBS. The Biotrak Cell Proliferation ELISA System Version 2 (Amersham Pharmacia Biotech, Uppsala, Sweden) was used for the cell proliferation assay. Briefly, cells were incubated in 5-bromo-2'-deoxyuridine (BrdU) labelling solution. Following cell fixation and DNA denaturation, specimens were incubated in peroxidase-labelled anti-BdrU. Subsequently, 3,3',5,5'-tetramethylbenzidine was added as a substrate to detect immune complexes. Absorbance was calculated from the absorbance at $450 \mathrm{~nm}$ measured using a microtitre plate reader.

\section{Assay for colony formation in soft agar (anchorage- independent growth)}

Colony formation in semisolid agar was assayed by suspending $4 \times 10^{3}$ cells in $2 \mathrm{ml}$ of DMEM/F12/10\% FBS with $0.33 \%$ agarose (Sigma-Aldrich) and placing this suspension on top of $2 \mathrm{ml}$ of solidified $0.5 \%$ agarose in the above medium. Six cultures for each cell type were maintained for 21 days at $37^{\circ} \mathrm{C}$ in a $5 \% \mathrm{CO}_{2}$ atmosphere with fresh medium changed every 1 week. Colonies larger than $100 \mu \mathrm{m}$ in diameter were counted after a lapse of 3 weeks. The experiments were repeated three times.

\section{Assay for tumour formation in athymic $n u / n u$ mice}

Female athymic BALB/cA $n u / n u$ mice, aged 4 weeks and weighting 15-18 g, were obtained from CLEA Japan (Tokyo, Japan). Mice were maintained in a clean box at $22 \pm 2{ }^{\circ} \mathrm{C}$ and $50-70 \%$ humidity on a $12 \mathrm{~h}$ light-dark cycle. Gamma-ray-irradiated solid food was provided by Oriental Yeast (Tokyo, Japan), and drinking water was acidified with $\mathrm{HCl}$ to a $\mathrm{pH}$ of $2.5-3.0$. All procedures in this assay were approved by the Center for Animal Resources and Development of Graduate School of Medical Science, Kumamoto University.

Cells of E7/hTERT and OVCAR-3 were harvested with trypsin: EDTA, and the pellet of cells obtained by centrifugation was suspended in growth medium $\left(3.6 \times 10^{7}\right.$ cells ml $\left.^{-1}\right)$. Aliquots $(0.1 \mathrm{ml})$ were injected subcutaneously into the subscapular areas of athymic $\mathrm{BALB} / \mathrm{c} n u / n u$ mice and observed for tumorigenic growth every week for a 4-month period.

\section{Statistical analysis}

The Mann-Whiteney $U$-test was used to assess the differences in the proliferation assay. Differences were considered to be significant at $P<0.05$. This analysis was made using the StatView system (Abacus, Berkeley, CA, USA).

\section{RESULTS}

Telomerase and cell cycle regulator in primary human OSE and transduced cells

All transduced cells showed telomerase activity in a TRAP assay at passage 7 (data not shown). In primary human OSE cells, p16 protein levels were quite high as early as passage 4, and levels of p53 and p21 proteins increased through passage 4-6 (Figure 1). Expression of p53 and p21 proteins in all seven transduced HOSE1 cell groups were inhibited by harbouring E6 or E6 $\Delta 151$ (HOSE1s-E6/hTERT, -E6/E7/hTERT, -E6 $\Delta 151 /$ E7/hTERT, and $-\mathrm{E} 6 \Delta 151 / \mathrm{Bmi} / \mathrm{hTERT})$, while they were increased by E7 alone (HOSE1-E7/hTERT) when compared with those of primary cells (Figure 1). It could be supported by the fact that blockage of $\mathrm{Rb}$ pathway enhances p53 pathway via induction of p14ARF (Bates et al, 1998). The expression of p16 protein was slightly suppressed by Bmil alone (HOSE1-Bmil/hTERT), and was elevated in cells expressing E7 (HOSE1s-E7/hTERT, -E6/E7/hTERT and -E6 $151 /$ E7/hTERT), as E7 allowed high p16 levels through inactivation of $\mathrm{Rb}$ (Figure 1). Our data were consistent with previous studies that 
immortalised cells by inactivating $\mathrm{Rb}$ pathway introducing $\mathrm{E} 7$ highly expressed p53, p21, and p16 (Foster and Galloway, 1996; Kiyono et al, 1998; Jarrard et al, 1999; Mori et al, 2005).

\section{Long-term culture and immortalisation by transduction}

The two cell lines HOSE1s-hTERT and -Bmil/hTERT fell into senescence within passages 8-10, whereas the cells of HOSE1s-E6/hTERT, -E7/hTERT, -E6/E7/hTERT, -E6 151/E7/hTERT, and -E $6 \Delta 151 / \mathrm{Bmi1} / \mathrm{hTERT}$ grew beyond a population doubling number of 100 . Consequently, they were defined as immortalised cell lines. Moreover, these five cell lines are now growing with a population doubling number greater than 200. The doubling time (DT) of the HOSE1s cells was 23.4-36.9 h (Table 1). Furthermore, in the anchorage-dependent proliferation assay, cell proliferation of HOSE1s cells was significantly higher than that of primary human OSE cells $(P<0.05)$ (Figure 2$)$. The three cell lines, HOSE1s-E6/E7/ hTERT, -E6 $\Delta 151 / E 7 / h T E R T$, and -E6 $\Delta 151 / B m i 1 /$ hTERT, inhibited both $\mathrm{p} 16 / \mathrm{Rb}$ and $\mathrm{p} 53$, and showed shorter DT and possessed higher proliferative ability than -E6/hTERT and -E7/hTERT cells (Figure 2 and Table 1).

\section{Karyotype analysis}

Although HOSE1s-E6/hTERT, -E6/E7/hTERT, -E6 $\Delta 151 /$ E7/hTERT, and -E6 $\Delta 151 /$ Bmil/hTERT exhibited almost normal chromosomal number with small deviation ranging between 42 and 48 in early passage (passage 16), they did show chromosomal alteration varying from 43 to 96 after immortalisation (passage 41) (Table 2A). HOSE1-E7/hTERT alone revealed normal diploidy in both passages (Figure 3 and Table 2B). In late passage (passage 41), the G-banded karyotype of this cell line was normal in five of 12 cells, 46, XX, showed minor structural alteration including 46, $\mathrm{XX}, \mathrm{t}(7 ; 7)(\mathrm{p} 10 ; \mathrm{p} 10)$ in five of 12 cells, and showed 46, idem, $-\mathrm{X},+\mathrm{i}(\mathrm{X})(\mathrm{p} 10), \operatorname{add}(1)(\mathrm{p} 36), \operatorname{add}(10)(\mathrm{p} 11)$ in two of 12 cells (Table 2B). Futhermore, karyotype of the HOSE1-E7/hTERT cells at passage 60 was additionally analysed. All 50 cells revealed also diploidy and the G-banded karyotype of this was 46, XX in three of 13 cells and showed a minor structural alteration indicated $46, \mathrm{XX}$, $\mathrm{t}(7 ; 7)(\mathrm{p} 10 ; \mathrm{p} 10)$ in 10 of 13 cells.

\section{Morphological characterisation}

The growth patterns of HOSE1s cells on culture dishes were morphologically divided into two phenotypes (Figure 4 and Table 1). One was a 'flat-epithelial type' and was defined as a cobblestone arrangement of cuboidal epithelial-like monolayer cells, similar to the growth pattern of primary human OSE cells. The other was a 'fibroblast-like type' and was defined as an atypical or fusiform pattern. The growth patterns of HOSE1s-E7/ hTERT, -E6/E7/hTERT, and -E6 $\Delta 151 / E 7 / h T E R T$ were classified as 'flat-epithelial type', while those of immortalised HOSE1s-E6/ hTERT and -E6 $\Delta 151 / \mathrm{Bmi1} / \mathrm{hTERT}$ were classified as 'fibroblastlike type' (Figure 4 ).

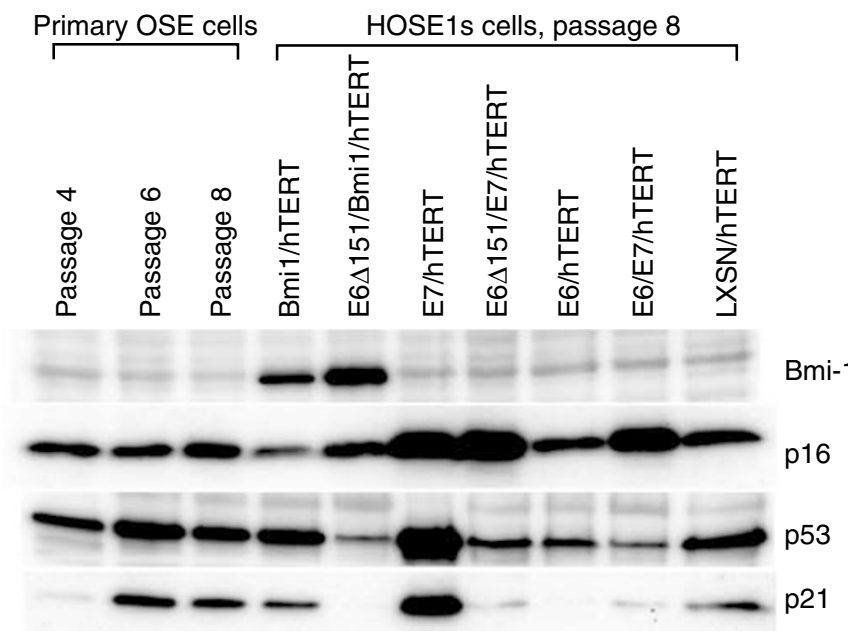

Figure I Western blot analysis of Bmil, p16, p53, and p2I proteins in primary human OSE cells and the immortalised HOSEIs cells. The left three lanes indicated primary human OSEs cells at passages 4, 6, and 8. The other seven lanes showed expression in the immortalised HOSEIs cells at passage 8. LXSN/hTERT was HOSEI cells transduced with hTERT alone.

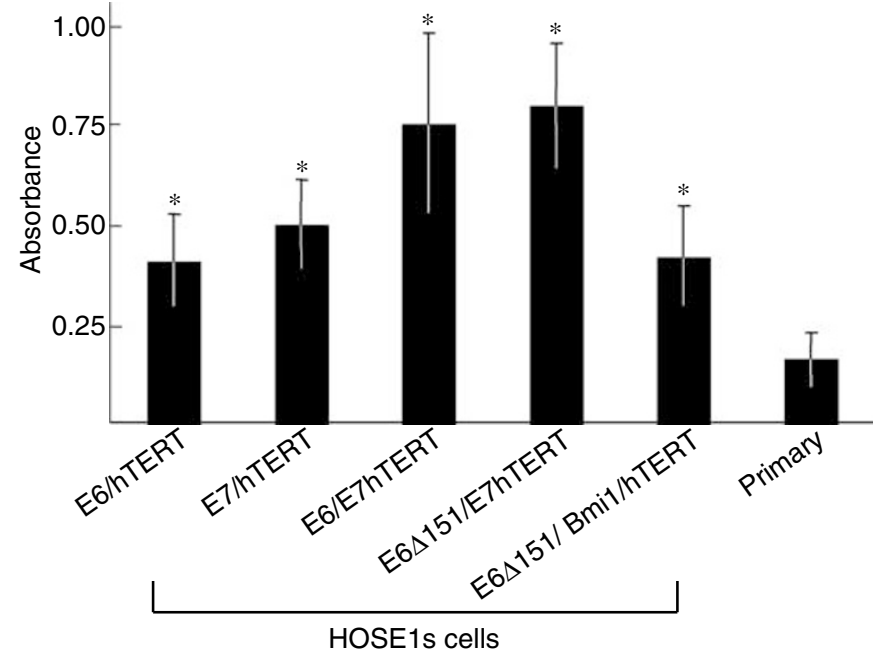

Figure 2 Cell proliferation assay of the immortalised HOSEIs cells and primary OSE cells. Data represented the absorbance of each cell type. Individual values were compared using Mann-Whitney's U-test and were significantly different from primary OSE cells (*; $P<0.05)$.

Table I Phenotype and growth of immortalised HOSEIs cells and ovarian cancer cell line (OVCAR-3)

\begin{tabular}{|c|c|c|c|c|c|}
\hline & $\begin{array}{l}\text { Morphological } \\
\text { type }\end{array}$ & $\begin{array}{l}\text { Doubling } \\
\text { time (h) }\end{array}$ & $\begin{array}{c}\text { Population } \\
\text { doubling level }\end{array}$ & $\begin{array}{l}\text { Colony efficiency } \\
\text { in soft agar (\%) }\end{array}$ & $\begin{array}{l}\text { Tumour formation } \\
\text { in nu/nu mice }\end{array}$ \\
\hline E6/hTERT & Fibroblastic & 36.9 & 204 & $0.08 \pm 0.08$ & N.E. \\
\hline E7/hTERT & Epithelial & 35.1 & 242 & $0.00 \pm 0.00$ & $0 / 5$ \\
\hline E6/E7/hTERT & Epithelial & 26.1 & 210 & $0.08 \pm 0.10$ & N.E. \\
\hline E6 $\Delta / 5 \mathrm{I} / \mathrm{E} 7 / \mathrm{hTERT}$ & Epithelial & 23.4 & 245 & $1.55 \pm 0.36$ & N.E. \\
\hline E6 $\Delta / 5 \mid / B m i l / h T E R T$ & Fibroblastic & 29.7 & 204 & $0.02 \pm 0.04$ & N.E. \\
\hline OVCAR-3 & Epithelial & N.E. & N.E. & $49.05 \pm 5.22$ & $4 / 5$ \\
\hline
\end{tabular}

N.E. = not examined. 
Table 2 Chromosomal analysis of immortalised HOSEIs cells: (A) Chromosomal numbers of immortalised HOSEIs cells; (B) Karyotype analysis of immortalised HOSEIs cells

(A) Chromosome number

\begin{tabular}{lcc}
\cline { 2 - 3 } Cell lines & Passage $\mathbf{~ 1 6}$ & Passage 4I \\
\hline E6/hTERT & $42-48$ & $43-87$ \\
E7/hTERT & $46-47$ & 46 \\
E6/E7/hTERT & $43-48$ & $43-55$ \\
E6 I II/E7/hTERT & $46-47$ & $84-96$ \\
E6 $/ 5$ I/Bmil/hTERT & $42-46$ & $58-92$ \\
\hline
\end{tabular}

Cell lines

E6/hTERT

E6/ET/hTERT

E6 $15 / /$ ET/hTERT

E6 $\Delta / 5 \mathrm{I} / \mathrm{Bmil} / \mathrm{hTERT}$

\section{(B) Karyotype analysis}

63-87 <3n >, $X X,-X[10], \operatorname{add}(X)(q 22)[2],+2[2],+3[3],-4[10], \operatorname{add}(4)(q 35)[7],+5[9],+6[2],+7[8],+8[10],+8[6],+9[7]$,

$+10[7],+11[9],+12[4], \operatorname{add}(12)(q 24)[7],-13[9],-14[9],-15[8],+16[9],-17[5],+18[6], \operatorname{add}(18)(q 21)[5],+19[7]$,

$+19[2],+20[10],+20[9],+20[5],+21[10],+22[7],+22[2],+\operatorname{marl}[2],+\operatorname{mar} 2[3]$

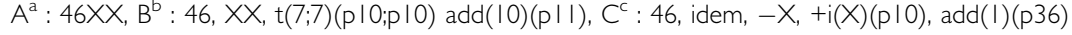

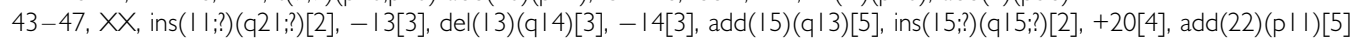

$88-93<4 n>, X X X X, \operatorname{del}(X)(q 2$ ?) [3], i ( $)(p \mid 0)[8],-2[10],-4[3],+5[7],+6[7],-10[4], \operatorname{add}(10)(p \mid l)[5],+12[9],-13[9],-13[3]$,

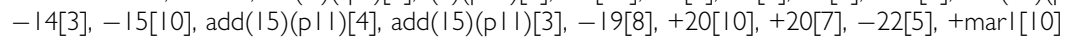

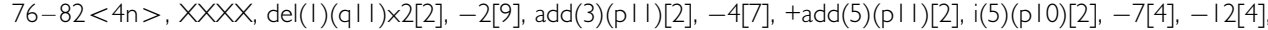

$\operatorname{add}(12)(\mathrm{pll})[3], \operatorname{del}(\mathrm{I} 2)(\mathrm{p} \mid \mathrm{I})[2],-13[10],-13[9],-15[9],-16[8],-16[4],-17[8],-17[5],-18[8],-18[3],-19[7],-22[5]$,

+ marl [2]

The numbers of cells were ${ }^{a} 5,{ }^{b} 5$, and ${ }^{c} 2$ of 12 cells.

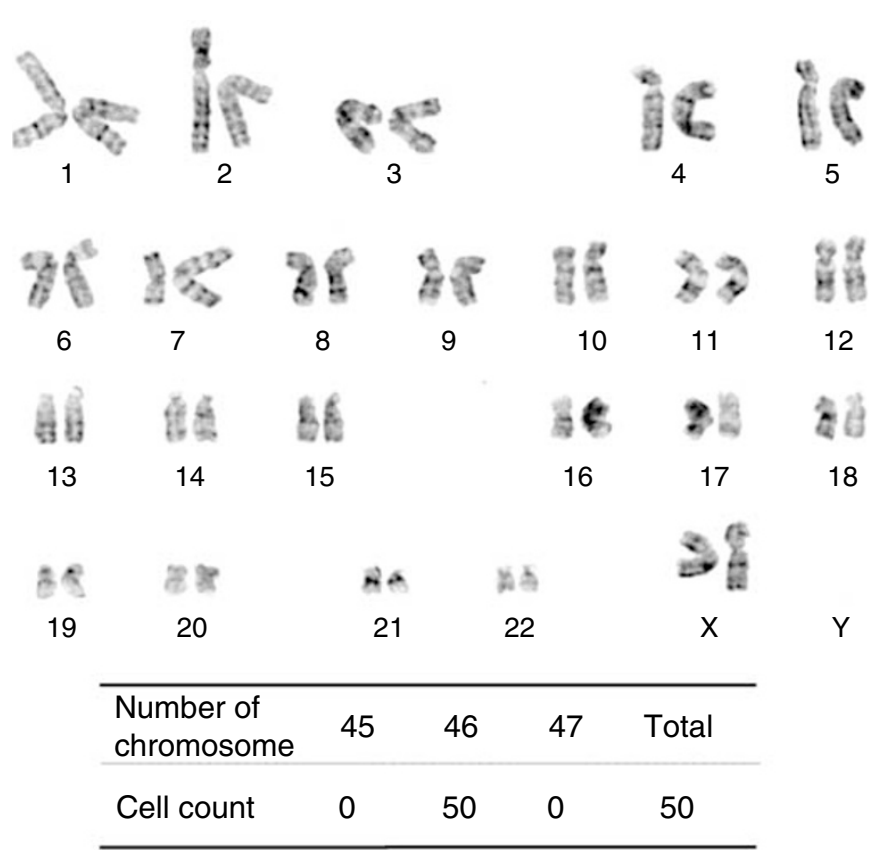

Figure 3 Karyotype of HOSEI-E7/hTERT cells. The chromosomal number was diploid after long-term culture (passage number 4I; population doubling |42).

\section{Immunocytochemical characterization for cytoskeleton component}

In immunocytochemistry, HOSE1s cells except for HOSE1-E6/ hTERT expressed cytokeratin, vimentin, and collagen IV, but did not express EMA, similar to the primary human OSE cells (Table 3). The cells of HOSE1-E6/hTERT expressed vimentin and collagen IV, but did not express cytokeratin or EMA (Table 3).

\section{E-cadherin expression}

The expression of E-cadherin in HOSE1s cells and an ovarian cancer cell line was examined by RT - PCR. The ovarian cancer cell line, OVCAR-3, expressed the mRNA of E-cadherin, but none of the HOSE1s cells did, identical to the primary OSE cells (data not shown).

\section{CA125 secretion}

None of the HOSE1s cells expressed CA125 in immunocytochemistry, as with the primary OSE cells, while the ovarian cancer cell line, OVCAR-3, did (Table 1). Correspondingly, the HOSE1s cells secreted little CA125 $\left(1.83 \pm 0.21-2.03 \pm 0.26 \mathrm{IUl}^{-1}\right)$ and OVCAR-3 highly produced CA125 $\left(1216.67 \pm 76.38 \mathrm{IU}^{-1}\right)$ in culture media.

\section{Colony formation and tumour formation in HOSE1s cells}

The anchorage-independent growth property of HOSE1s cells was examined by the colony formation assay in soft agar. The colony efficiency of HOSE s-E6/hTERT, -E7/hTERT, -E6/E7/ hTERT, -E6 $\Delta 151 /$ E7/hTERT, and -E6 $\Delta 151 /$ Bmil/hTERT was 0.08 , $0.00,0.08,1.55$, and $0.02 \%$, respectively. Correspondingly, the efficiency of OVCAR-3 was $49.05 \pm 5.22 \%$ (Table 1 ).

The cells of HOSE1-E7/hTERT and OVCAR-3 cells were injected subcutaneously into the subscapular areas of athymic $n u / n u$ mice. Although tumour formation $(>1 \mathrm{~cm})$ was observed in four of the five mice injected with OVCAR- 3 within 4 months, no tumours were found in the mice injected with HOSE1-E7/hTERT (Table 1).

\section{DISCUSSION}

Telomere loss was previously considered to be the sole factor governing senescence since transduction of hTERT was sufficient to immortalize human fibroblasts of mesenchymal cells (Bodnar et al, 1998). However, other factors were also thought to be involved in senescence of human epithelial cells because several kinds of epithelial cells were unable to be immortalised by telomerase activation alone (Kiyono et al, 1998; Kyo et al, 2003). It 

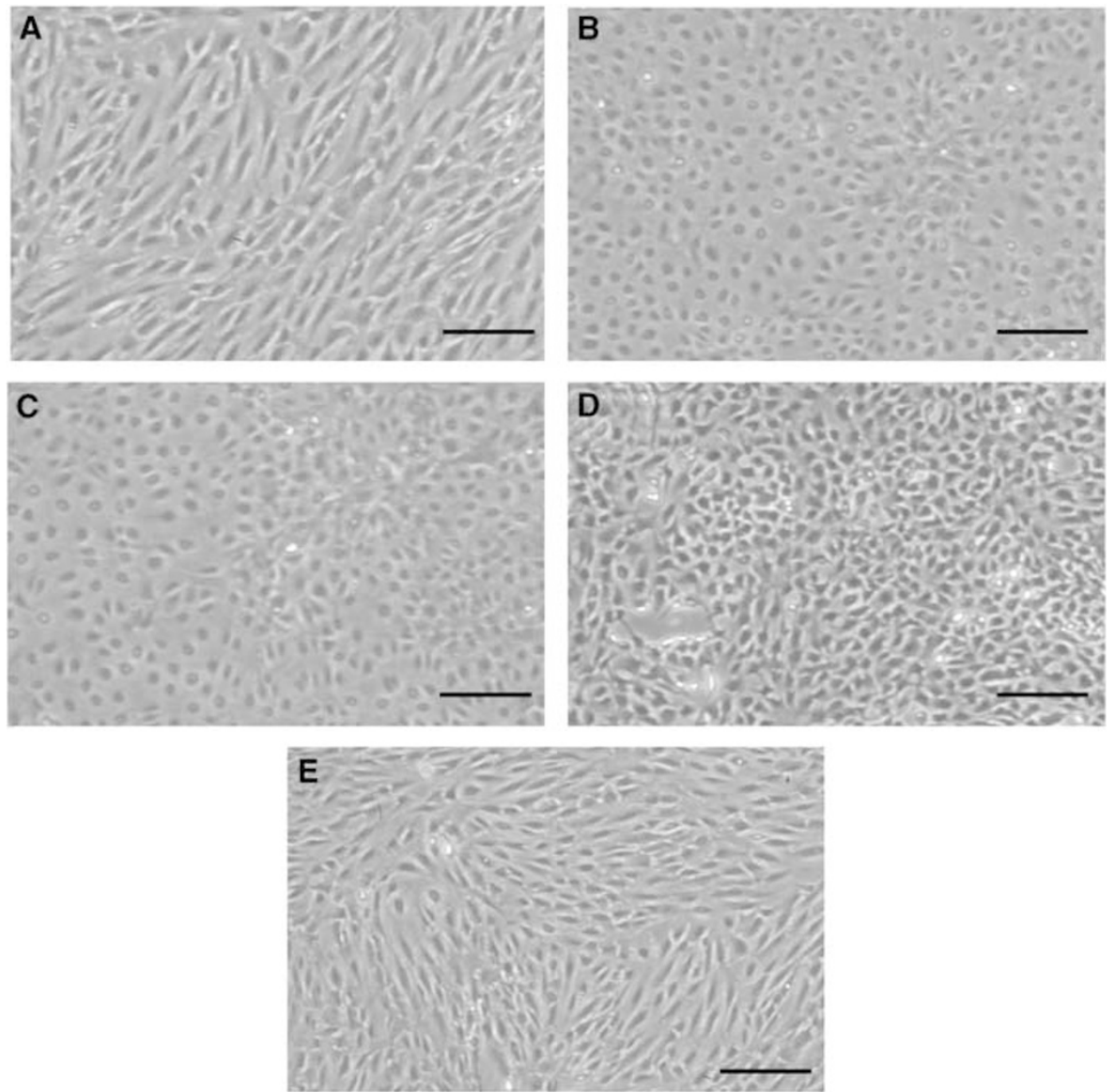

Figure 4 Morphological phenotype of immortalised HOSEI-E6/hTERT, -E7/hTERT, -E6/E7/hTERT, -E6 $/ 5 \mathrm{II/E7/hTERT} \mathrm{and} \mathrm{-E6 \Delta I5I/Bmil/hTERT.}$ Passage number of all HOSEI cells was 40. The morphological phenotypes of HOSEI-E7/hTERT (B), -E6/E7/hTERT (C) and -E6 I 5I/E7/hTERT (D) were 'flat-epithelial type', while those of HOSE Is-E6/hTERT (A) and -E6 $15 \mathrm{I} / \mathrm{Bmil} / \mathrm{hTERT}(\mathbf{E})$ were 'fibroblast-like type'. Scale bar $=100 \mu \mathrm{m}$.

Table 3 Immunocytochemical profile of immortalised HOSEIs cells

Cytokeratin Vmientin EMA ${ }^{\mathrm{a}}$ Colllagen IV CAI25

\begin{tabular}{|c|c|c|c|c|c|}
\hline Primary OSE cells & + & + & - & + & - \\
\hline E6/hTERT & - & + & - & + & - \\
\hline E7/hTERT & + & + & - & + & - \\
\hline E6/E7/hTERT & + & + & - & + & - \\
\hline E6 6 I I I/E7/hTERT & + & + & - & + & - \\
\hline E6 $\Delta / 5 \mid / B m i l / h T E R T$ & + & + & - & + & - \\
\hline
\end{tabular}

${ }^{a} E M A=$ epithelial membrane antigen. $+=$ positive, $-=$ negative.

has been generally assumed that the mortality of epithelial cells is attributed to three stages (Foster and Galloway, 1996; Foster et al, 1998): M0 for activation of the $\mathrm{p} 16 / \mathrm{Rb}$ pathway, M1 for telomere shortening and activation of the $\mathrm{p} 53 / \mathrm{p} 21$ pathway, and $\mathrm{M} 2$ for further shortening of telomeres in cells with inactivated p53/p21 pathway (Shay et al, 1991; Wright and Shay, 1992; Foster and Galloway, 1996; Foster et al, 1998).

OSE have the same origin as peritoneal mesothelial cells covering the intraperitoneal organs and have the properties of both epithelial and mesenchymal cells (Okamura and Katabuchi, 2005). Lately, the lifespan of human OSE cells was reported to be prolonged by telomerase activation alone, but the OSE cells were unable to be immortalised similarly to the epithelial cells (Alvero et al, 2004). Thereby, inhibition of the three stages, alone or in combination, was added to our experimental design for immorta- lisation of the mesothelial OSE cells. In particular, we transduced Bmil (Jacobs et al, 1999), E7, and E6 for inhibition of p16, Rb, and p53, respectively, as well as hTERT for activation of telomerase.

In the study presented here, five cell lines except for two lines of HOSE1s-Bmil/hTERT and -hTERT were immortalised and grew over a population doubling level of 200 . Both inhibitors of $\mathrm{p} 16 / \mathrm{Rb}$ and p53 in combination with hTERT highly enhanced cell proliferation, and induced immortalisation. In addition, either E7 alone for p16/Rb inhibition, or E6 alone for p53 inhibition, in combination with hTERT, less enhanced it than both inhibitors. Nevertheless, their combination also successfully immortalised the OSE cells with slow cell growths.

Cell immortalisation maintaining chromosomal stability was the primary aim of the present study. After immortalisation, chromosomal analysis showed diploidy in the HOSE1-E7/hTERT cell line alone. Chromosomal alteration was revealed in the other cell lines despite hTERT-transduction to abolish chromosomal crisis. Interestingly, similar results have been reported for preadipocytes and bone marrow stromal cells immortalised by introduction of E7 and hTERT (Darimont et al, 2003; Mori et al, 2005). In these immortalised cells, functional p53 was induced by E7 probably through upregulation of p14ARF (Bates et al, 1998). The active p53 could have prevented chromosomally abnormal cells from emerging and proliferating. Conversely, inactivation of p53 induces chromosomal alteration by abnormal centrosome amplification (Fukasawa et al, 1996), and abolishes DNA damage checkpoint and p53-dependent apoptosis. The other cell lines immortalised with the help of E6 or E6 $\Delta 151$ might have greater 
chance to accumulate chromosomal changes as a result of inactivated $\mathrm{p} 53$.

OSE have the properties of both epithelial and mesenchymal cells from the viewpoint of embryonal development, as described above. Cultured OSE cells have been shown to be highly responsive to environmental influences, and to exhibit mesenchymal morphology at each passage under standard culture conditions (Auersperg et al, 1994, 2001), that is, epithelio-mesenchymal transition (EMT). In the present study, the immortalised HOSE1s cells grew as flat epithelial cells or fibroblast-like cells. Among them, HOSE1-E7/hTERT without chromosomal instability showed flat epithelial phenotype. Immunocytochemically, the immortalised HOSE1s cells have the same cytoskeletal properties as the primary HOSE1 cells, except for cytokeratin negativity in HOSE1E6/hTERT cells. The negativity would account EMT in cultured condition (Auersperg et al, 1994). However, the possibility of contamination of the stromal cells by scraping method would not be denied.

Previously, OSE cells were shown to become more firmly committed to an epithelial phenotype in the process of malignant transformation (Maines-Bandiera et al, 1992; Auersperg et al, 1994). Similar to primary human OSE cells, our immortalised HOSE1 cells did not express E-cadherin or CA125, which were expressed in the ovarian cancer cell line, OVCAR-3 (van Niekerk et al, 1989; Auersperg et al, 1999). In addition, to examine whether the immortalised HOSE1 cells were transformed, they were tested for anchorage-independent growth in a soft agar and assayed for tumorigenicity in athymic $n u / n u$ mice. HOSE1-E7/hTERT, with a normal chromosomal number, did not form any colonies in soft agar medium or tumours in athymic $n u / n u$ mice. Consequently, this cell line was concluded not to have major transformed phenotype.

We have been the first to establish a transduced HOSE1 cell line (HOSE1-E7/hTERT) that have no major chromosomal alterations or transformation activity. Immortalised HOSE1-E7/hTERT could now serve as a relevant model for investigation of the molecular aetiology of epithelial ovarian carcinomas, identifying markers of tumour progression. The process of ovarian carcinogenesis should also be revealed using this system.

\section{ACKNOWLEDGEMENTS}

This work was supported by a Grant-in-Aid for Scientific Research (12671616) from Japan Society for the Promotion of Science.

\section{REFERENCES}

Alvero AB, Fishman DA, Qumsiyeh MB, Garg M, Kacinski BM, Sapi E (2004) Telomerase prolongs the lifespan of normal human ovarian surface epithelial cells without inducing neoplastic phenotype. J Soc Gynecol Investig 11: 553 - 561

Auersperg N, Maines-Bandiera SL, Dyck HG, Kruk PA (1994) Characterization of cultured human ovarian surface epithelial cells: phenotypic plasticity and premalignant changes. Lab Invest 71: 510-518

Auersperg N, Pan J, Grove BD, Peterson T, Fisher J, Maines-Bandiera S, Somasiri A, Roskelley CD (1999) E-cadherin induces mesenchymal-toepithelial transition in human ovarian surface epithelium. Proc Natl Acad Sci USA 96: 6249-6254

Auersperg N, Wong AS, Choi KC, Kang SK, Leung PC (2001) Ovarian surface epithelium: biology, endocrinology, and pathology. Endocr Rev 22: $255-288$

Bates S, Phillips AC, Clark PA, Stott F, Peters G, Ludwig RL, Vousden KH (1998) p14ARF links the tumour suppressors RB and p53. Nature 395: $124-125$

Bellacosa A, de Feo D, Godwin AK, Bell DW, Cheng JQ, Altomare DA, Wan M, Dubeau L, Scambia G, Masciullo V (1995) Molecular alterations of the AKT2 oncogene in ovarian and breast carcinomas. Int J Cancer 64: $280-285$

Blackburn EH (1991) Structure and function of telomeres. Nature 350: $569-573$

Bodnar AG, Ouellette M, Frolkis M, Holt SE, Chiu CP, Morin GB, Harley CB, Shay JW, Lichtsteiner S, Wright WE (1998) Extension of life-span by introduction of telomerase into normal human cells. Science 279: 349-352

Darimont C, Zbinden I, Avanti O, Leone-Vautravers P, Giusti V, Burckhardt P, Pfeifer AM, Mac K (2003) Reconstitution of telomerase activity combined with HPV-E7 expression allow human preadipocytes to preserve their differentiation capacity after immortalization. Cell Death Differ 10: 1025-1031

Enomoto T, Weghorst CM, Inoue M, Tanizawa O, Rice JM (1991) K-ras activation occurs frequently in mucinous adenocarcinomas and rarely in other common epithelial tumors of the human ovary. Am J Pathol 139: $777-785$

Foster SA, Galloway DA (1996) Human papillomavirus type 16 E7 alleviates a proliferation block in early passage human mammary epithelial cells. Oncogene 12: 1773 - 1779

Foster SA, Wong DJ, Barrett MT, Galloway DA (1998) Inactivation of p16 in human mammary epithelial cells by $\mathrm{CpG}$ island methylation. Mol Cell Biol 18: $1793-1801$

Fujita M, Enomoto T, Yoshino K, Nomura T, Buzard GS, Inoue M, Okudaira Y (1995) Microsatellite instability and alterations in the hMSH2 gene in human ovarian cancer. Int J Cancer 64: $361-366$

Fukasawa K, Choi T, Kuriyama R, Rulong S, Vande Woude GF (1996) Abnormal centrosome amplification in the absence of p53. Science 271: $1744-1747$

Jacobs JJ, Kieboom K, Marino S, DePinho RA, van Lohuizen M (1999) The oncogene and Polycomb-group gene bmi-1 regulates cell proliferation and senescence through the ink4a locus. Nature 397: 164-168

Jarrard DF, Sarkar S, Shi Y, Yeager TR, Magrane G, Kinoshita H, Nassif N, Meisner L, Newton MA, Waldman FM, Reznikoff CA (1999) p16/pRb pathway alterations are required for bypassing senescence in human prostate epithelial cells. Cancer Res 59: 2957-2964

Kiyono T, Foster SA, Koop JI, McDougall JK, Galloway DA, Klingelhutz AJ (1998) Both Rb/p16INK4a inactivation and telomerase activity are required to immortalize human epithelial cells. Nature 396: $84-88$

Kiyono T, Hiraiwa A, Fujita M, Hayashi Y, Akiyama T, Ishibashi M (1997) Binding of high-risk human papillomavirus E6 oncoproteins to the human homologue of the Drosophila discs large tumor suppressor protein. Proc Natl Acad Sci USA 94: 11612-11616

Kyo S, Nakamura M, Kiyono T, Maida Y, Kanaya T, Tanaka M, Yatabe N, Inoue M (2003) Successful immortalization of endometrial glandular cells with normal structural and functional characteristics. Am J Pathol 163: $2259-2269$

Maines-Bandiera SL, Kruk PA, Auersperg N (1992) Simian virus 40 transformed human ovarian surface epithelial cells escape normal growth controls but retain morphogenetic responses to extracellular matrix. Am J Obstet Gynecol 167: 729-735

McCoy ML, Mueller CR, Roskelley CD (2003) The role of the breast cancer susceptibility gene 1 (BRCA1) in sporadic epithelial ovarian cancer. Reprod Biol Endocrinol 1: 72

Mori T, Kiyono T, Imabayashi H, Takeda Y, Tsuchiya K, Miyoshi S, Makino H, Matsumoto K, Saito H, Ogawa S, Sakamoto M, Hata J-i, Umezawa A (2005) Combination of hTERT and Bmi-1, E6 or E7 induce prolongation of the life span of bone marrow stromal cells from an elderly donor without affecting their neurogenic potential. Mol Cell Biol 25: 5183-5195

Nakamura M, Katabuchi H, Ohba T, Fukumatsu Y, Okamura H (1994) Isolation, growth and characteristics of human ovarian surface epithelium. Virchows Arch 424: 59-67

Naviaux RK, Costanzi E, Haas M, Verma IM (1996) The pCL vector system: rapid production of helper-free, high-titer, recombinant retroviruses. J Virol 70: $5701-5705$

Nishida M, Kawai K, Tanaka M, Tegoshi T, Arizono N (2003) Expression of E-cadherin in human mast cell line HMC-1. APMIS 111: $1067-1074$

Nitta M, Katabuchi H, Ohtake H, Tashiro H, Yamaizumi M, Okamura H (2001) Characterization and tumorigenicity of human ovarian surface 
epithelial cells immortalized by SV40 large T antigen. Gynecol Oncol 81: $10-17$

Obata K, Morland SJ, Watson RH, Hitchcock A, Chenevix-Trench G, Thomas EJ, Campbell IG (1998) Frequent PTEN/MMAC mutations in endometrioid but not serous or mucinous epithelial ovarian tumors. Cancer Res 58: 2095-2097

Okamoto T, Aoyama T, Nakayama T, Nakamata T, Hosaka T, Nishijo K, Nakamura T, Kiyono T, Toguchida J (2002) Clonal heterogeneity in differentiation potential of immortalized human mesenchymal stem cells. Biochem Biophys Res Commun 295: 354-361

Okamura H, Katabuchi H (2005) Pathophysiological dynamics of human ovarian surface epithelial cells in epithelial ovarian carcinogenesis. Int Rev Cytol 242: 1-54

Ong A, Maines-Bandiera SL, Roskelley CD, Auersperg N (2000) An ovarian adenocarcinoma line derived from SV40/E-cadherin-transfected normal human ovarian surface epithelium. Int J Cancer 85: 430 - 437

Paige AJ, Taylor KJ, Taylor C, Hillier SG, Farrington S, Scott D, Porteous DJ, Smyth JF, Gabra H, Watson JE (2001) WWOX: a candidate tumor suppressor gene involved in multiple tumor types. Proc Natl Acad Sci USA 98: $11417-11422$

Schorge JO, Miller YB, Qi LJ, Muto MG, Welch WR, Berkowitz RS, Mok SC (2000) Genetic alterations of the WT1 gene in papillary serous carcinoma of the peritoneum. Gynecol Oncol 76: 369-372

Shay JW, Wright WE, Werbin H (1991) Defining the molecular mechanisms of human cell immortalization. Biochim Biophys Acta 1072: 1-7

Shayesteh L, Lu Y, Kuo WL, Baldocchi R, Godfrey T, Collins C, Pinkel D, Powell B, Mills GB, Gray JW (1999) PIK3CA is implicated as an oncogene in ovarian cancer. Nat Genet 21: 99-102

Slamon DJ, Godolphin W, Jones LA, Holt JA, Wong SG, Keith DE, Levin WJ, Stuart SG, Udove J, Ullrich A (1989) Studies of the HER-2/ neu proto-oncogene in human breast and ovarian cancer. Science 244: $707-712$
Tashiro H, Katabuchi H, Begum M, Li X, Nitta M, Ohtake H, Okamura H (2003) Roles of luteinizing hormone/chorionic gonadotropin receptor in anchorage-dependent and -independent growth in human ovarian surface epithelial cell lines. Cancer Sci 94: 953-959

Tashiro H, Miyazaki K, Okamura H, Iwai A, Fukumoto M (1992) C-myc over-expression in human primary ovarian tumours: its relevance to tumour progression. Int J Cancer 50: 828-833

Tsao SW, Mok SC, Fey EG, Fletcher JA, Wan TS, Chew EC, Muto MG, Knapp RC, Berkowitz RS (1995) Characterization of human ovarian surface epithelial cells immortalized by human papilloma viral oncogenes (HPV-E6E7 ORFs). Exp Cell Res 218: 499-507

van Niekerk CC, Jap PH, Thomas CM, Smeets DF, Ramaekers FC, Poels LG (1989) Marker profile of mesothelial cells versus ovarian carcinoma cells. Int J Cancer 43: 1065 - 1071

Wiener JR, Windham TC, Estrella VC, Parikh NU, Thall PF, Deavers MT, Bast RC, Mills GB, Gallick GE (2003) Activated SRC protein tyrosine kinase is overexpressed in late-stage human ovarian cancers. Gynecol Oncol 88: $73-79$

Wong AS, Pelech SL, Woo MM, Yim G, Rosen B, Ehlen T, Leung PC, Auersperg N (2001) Coexpression of hepatocyte growth factor-Met: an early step in ovarian carcinogenesis? Oncogene 20: 1318-1328

Wright WE, Shay JW (1992) The two-stage mechanism controlling cellular senescence and immortalization. Exp Gerontol 27: 383-389

Yu Y, Xu F, Peng H, Fang X, Zhao S, Li Y, Cuevas B, Kuo WL, Gray JW, Siciliano M, Mills GB, Bast RC (1999) NOEY2 (ARHI), an imprinted putative tumor suppressor gene in ovarian and breast carcinomas. Proc Natl Acad Sci USA 96: 214-219

Zakian VA (1989) Structure and function of telomeres. Annu Rev Genet 23: $579-604$

Zhou H, Kuang J, Zhong L, Kuo WL, Gray JW, Sahin A, Brinkley BR, Sen S (1998) Tumour amplified kinase STK15/BTAK induces centrosome amplification, aneuploidy and transformation. Nat Genet 20: 189-193 